\title{
Decomposing the Changes in Water Intensity in a Mediterranean Region
}

\author{
Maria Llop ${ }^{1}$ \\ Received: 6 November 2018 / Accepted: 12 May 2019/ \\ Published online: 25 May 2019 \\ (C) The Author(s) 2019
}

\begin{abstract}
This paper proposes a new method for decomposing temporal changes in water use intensity (i.e. quantity of water consumption divided by GDP) into various explanatory factors. Specifically, the changes are decomposed into three elements that clarify some of the hidden reasons behind changes in water use over time. The first one captures changes in water intensity due to sectoral uses, showing the effects of modifying water intensity in the various production sectors. The second shows the changes in sectoral output intensity, showing how altering the production structure affects water consumption. Finally, the third quantifies the effects of changes in residential water intensity, showing how changing the final water uses affects water intensity. The empirical application corresponds to the Spanish region of Catalonia. The results show a reduction in regional water intensity due to a negative contribution from the production structure and residential uses of water, which were greater than the increase in sectoral water intensity. This decomposition shows that the reduced importance of agricultural production had the greatest influence on the reduction in water intensity in this region. The directions and magnitudes of the components identified in this paper highlight the importance of using precise and detailed methods to study water issues.
\end{abstract}

Keywords Sectoral water intensity · Sectoral output intensity · Residential water intensity · Mediterranean region

\section{Introduction}

Freshwater is an essential natural resource that, since it is used both for drinking and for cultivating food sources, ensures human survival. Freshwater also provides the means for cleaning and personal hygiene, which facilitate an acceptable quality of life.

Water intensity, calculated as the quantity of water in relation to GDP, is a measure of the efficiency of the use of this resource. It is used by international organizations to estimate water

Maria Llop

maria.llop@urv.cat

1 Universitat Rovira i Virgili and CREIP, Avinguda Universitat n ${ }^{\circ} 1,43204$ Reus, Spain 
pressure and water consumption. The European Environment Agency (EEA 2017), the United Nations (2006) and other international institutions have calculated water intensities for countries, economic activities and regions of the world.

Water intensity has also been used in the literature to analyse numerous socioeconomic and environmental issues. For instance, Wang and Wang (2005) studied changes in the proportion of agricultural water to total water used in Beijing. Ostos and Tello (2014) analysed the longterm evolution of water intensity in the Mediterranean city of Barcelona. Spang et al. (2014) quantified water consumption for energy production worldwide. Zhang and Zhang (2014) studied the trend in China's water use intensity by means of an index decomposition analysis. Di Cosmo et al. (2014) decomposed water intensity and compared water usages in European Union countries. Hadjikakou et al. (2015) compared water intensity for various tourist types in Cyprus. And more recently, Legesse et al. (2018) examined the impact of more efficient beef production on water use intensity in Canada.

In this paper we propose an aggregated accounting method to determine the contribution of various determinants behind the changes in water use intensity. For several reasons water intensity and its explaining factors are a major concern for both policy makers and water managers. First, water use intensity involves economic and ecological behaviours that should be taken into account individually when water measures are designed. Second, the water intensity of the various agents (i.e. consumers, firms and public administrations) shows individual efficiency patterns in the use of water that are difficult to identify in total measurements of water uses. Finally, detailed information regarding water use intensity is useful for making proposals for economic and regional planning that are compatible with environmental sustainability.

The novelty of the decomposition presented in this paper stems from the use of structural decomposition analysis (SDA) to disentangle water use intensity. This reveals how various determinants encompassing distinct economic meanings contribute to changing regional water intensity. ${ }^{1}$ In particular, the changes in total water intensity are divided into three components with different meanings: changes in the (individual) water use intensity of production sectors, changes in sectoral output composition, and changes in residential water use intensity. Determining how an economy's water use intensity evolves over time is interesting for reducing water pressure. Moreover, if we understand the reasons for these (hidden) changes in water use intensity, we can define water measures that consider the automatic mechanisms governing water use (i.e. changes in water demand and modifications in production structure).

The proposed method is empirically applied to Catalonia. Catalonia is a typical Mediterranean region with limited water resources that depend considerably on rainfall. ${ }^{2}$ The Catalan population is concentrated along the coast while water resources are mainly located in the mountains. The region therefore suffers from permanent imbalances between water resources (i.e. water availability) and water requirements (i.e. water demand). In the last few decades,

\footnotetext{
${ }^{1}$ Among other SDA contributions, see for example Gowdy and Miller (1987) for US energy uses, Han and Lakshmanan (1994) for energy intensity in Japan, Rose and Casler (1996) for a revision of the SDA literature, Dietzenbacher and Los (1998) for solving problems related to the existence of multiple equivalent decompositions, Alcántara et al. (2010) for electricity consumption in Spain, Guerra and Sancho (2011) for changes in energy requirements and emissions in Spain, and Su and Ang (2012) for a comparison of SDA with index decomposition analysis (IDA) of energy emissions in China.

${ }^{2}$ Catalonia is a highly industrialised and dynamic region in the north-east of Spain. Covering approximately $6 \%$ of Spanish territory, it represents around $19 \%$ of Spanish GDP and 16\% of the Spanish population $(7,543,825$ inhabitants in 2018) (IDESCAT 2018).
} 
water scarcity has thus become an important question for the region's authorities, especially during periods of drought.

In the last few years, water issues in Catalonia have also received research attention. In particular, Llop (2013) proposed transforming the input-output framework to show water distribution among users within the Catalan economy, while Llop and Ponce-Alifonso (2015) used the input-output model of water consumption and defined a structural path analysis (SPA) method to determine more precisely the layers (and agents) responsible for the highest regional water uses. The computational general equilibrium (CGE) framework has also been used to analyse water issues in Catalonia to evaluate the economic impacts of alternative water management measures and changes in the agricultural productivity. ${ }^{3}$

To the best of my knowledge, this is the first study to propose an inter-annual approach for water analysis in Catalonia. For this economy little information is available on water statistics and, given theses data deficiencies, the years 2004 and 2007 define the period analysed in this paper. This limitation notwithstanding, the Catalan economy illustrates a similar water situation to that of other regions where imbalances between water availability and water requirements exist. The water pressure and water scarcity in Catalonia converts this region into a case study, whose results could be perfectly extrapolated to other Mediterranean regions and to areas of the world that suffer from water stress. In particular, the results presented in this paper will be useful for establishing directions for water management and water policy at a regional level in the near future, since they not only provide insights into the quantitative evolution of water use intensity but also identify some of the qualitative features involved (i.e. how water demand and output composition contribute to changes in water intensity).

The rest of the paper is organised as follows. The next section describes the decomposition method used to divide total changes in water intensity into several determinants and presents the data used. Section 3 discusses the empirical application to the Catalan economy, Section 4 reports the main results and the final section presents several concluding remarks.

\section{Methodology}

\subsection{Changes in Water Intensity and Decomposition}

Water intensity relates the physical uses of water to social and/or economic indicators. This calculation provides a relative measure of water consumption, that jointly links the ecological dimension of water use with economic activity and/or the social characteristics of the economy under consideration.

Several methods can be used to define water intensity. As the aim of this analysis is to determine various determinants within total intensity, the definition of water intensity individually considers 10 sectors of production $(j=1, \ldots, 10)$. This analysis also considers two components within total water demand $(D)$, as follows:

$$
D=\sum_{j=1}^{10} D_{j}+D_{r}
$$

where $D_{j}$ is the water demand for sector $j$, and $D_{r}$ is residential water demand, which specifically comprises the urban uses of water.

\footnotetext{
${ }^{3}$ Llop and Ponce-Alifonso $(2012,2016)$.
} 
By using the division in Expression (1), water intensity is defined as ${ }^{4}$ :

$$
w=\frac{D}{G D P}=\sum_{j=1}^{10} \frac{D_{j}}{G D P}+\frac{D_{r}}{G D P}=\sum_{j=1}^{10} \frac{D_{j}}{V A_{j}} \frac{V A_{j}}{G D P}+\frac{D_{r}}{G D P}=\sum_{j=1}^{10} w_{j} g_{j}+w_{r} .
$$

The term on the left side of Eq. (2) shows water intensity (w), i.e. total water demand $(D)$ divided by $G D P$. By denoting $V A_{j}$ as the value added of sector $j$, total water intensity is divided into sectoral water intensity $\left(\frac{D_{j}}{V A_{j}}=w_{j}\right)$ multiplied by the sectoral output intensity $\left(\frac{V A_{j}}{G D P}=g_{j}\right)$ plus the residential water intensity $\left(\frac{D_{r}}{G D P}=w_{r}\right)$. Using a similar method, Mendiluce et al. (2010) decomposed energy intensity in Spain. Unlike to the SDA decomposition proposed in Expression (2), however, the above authors decomposed the temporal changes in Spanish energy intensity using the Logarithmic Mean Divisia Index (LMDI). On the other hand, Di et al. (2014) used a (static) water intensity decomposition applied to European Union countries that did not differentiate the residential uses of water.

To study changes in water intensity, we need to compare two different time periods. Hereinafter, these periods are denoted using the subscripts 0 (first period, or 2004) and 1 (last period, or 2007). Moreover, as the variables involved correspond to different years, to avoid the distorting effects of price changes the inflationary effects inherent to the economic indicators must be removed.

Let us now assume that all the economic variables are at constant prices and that sectoral disaggregation is the same in both periods. By taking the first difference in Expression (2), changes in water intensity can be written as follows:

$$
\begin{gathered}
\Delta w=w_{1}-w_{0}=\sum_{j=1}^{10} w_{1, j} g_{1, j}+w_{1, r}-\sum_{j=1}^{10} w_{0, j} g_{0, j}-w_{0, r} \\
=\sum_{j=1}^{10} w_{1, j} \Delta g_{j}+\sum_{j=1}^{10} \Delta w_{j} g_{0, j}+\Delta w_{r} \\
=\sum_{j=1}^{10} \Delta w_{j} g_{1, j}+\sum_{j=1}^{10} w_{0, j} \Delta g_{j}+\Delta w_{r} .
\end{gathered}
$$

where $\Delta w, \Delta w_{j}, \Delta g_{j}$ and $\Delta w_{r}$ contain the first differences of the elements $w, w_{j}, g_{j}$, and $w_{r}$, respectively, and subscripts 0 and 1 denote the initial and final years. Note that although Expressions (3.a) and (3.b) are equivalent, the results will be different because the weights used to calculate the contribution of the increased components are different. Using an inputoutput model, Dietzenbacher and Los (1998) showed that the average of the two polar expressions provides a good approximation for the average of all possible expressions. If we take this idea into account, the average of Expression (3) can be written as:

$$
\Delta w=\sum_{j=1}^{10} \frac{1}{2} \Delta w_{j} g_{1, j}+\sum_{j=1}^{10} \frac{1}{2} w_{0, j} \Delta g_{j}+\Delta w_{r},
$$

where the term $\sum^{10} \frac{1}{2} \Delta w_{j} g_{1, j}$ shows the sectoral water intensity effect, $\sum^{10} \frac{1}{2} w_{0, j} \Delta g_{j}$ shows the

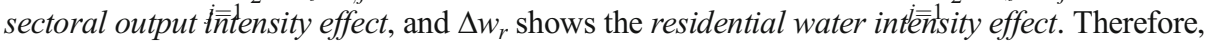

\footnotetext{
${ }^{4}$ Although residential water intensity is usually measured as water consumed per person, in Expression (2) residential water demand is related to GDP. This is to ensure that this component is compatible with sectoral water demand, and to enable a common relative indicator for the two components of water usages (i.e. water demand by sectors and water demand by consumers).
} 
in Expression (4) the changes in total water intensity $(\Delta w)$ are calculated as the addition of three different components with different economic meanings. The first component shows how changes in sectoral water uses have modified total water intensity; the second shows how changes in sectoral output composition have influenced water intensity; and the third shows how changes in residential water intensity have contributed to modifying total water intensity.

The simple decomposition proposed in Expression (4) helps to determine some of the reasons behind the changes in water uses. This method individually reflects the changes in variables with an ecological dimension (i.e. changes in sectoral and residential water intensities directly involving the water resources) and the changes in variables with an economic dimension (i.e. changes in the sectoral composition of regional output involving purely economic variables). Since both dimensions take place simultaneously, any water analysis should employ methods that are able to integrate the two perspectives affecting environmental issues (i.e. the economic and ecological dimensions).

\subsection{Data}

\subsubsection{Water Use in Catalonia}

Little statistical information is available on water use in Catalonia. The empirical application in this study is based on data available at a regional level, which include the water used by sectors and the final water consumption in 2004 and 2007. These years were chosen because they are the most recent years covered by regional water statistics. ${ }^{5}$

Water use is measured in cubic hectometres $\left(\mathrm{hm}^{3}\right)$ consumed by each production sector and by final users. For 2004, this information was obtained from two sources: Termes and Guiu (2009) provided the total water consumed in the region, ${ }^{6}$ while the Agència Catalana de l'Aigua (Catalan Water Agency) (ACA 2008) provided data on the water consumed by the production system. For 2007, all the information was published by the Agència Catalana de l'Aigua (ACA 2008).

Table 1 shows the information on water uses including water losses. ${ }^{7}$ If we compare uses during the period 2004-2007 we can see that there was a decrease of around $6.34 \%$ in the total amount of water consumed (from 3167 cubic hectometers in 2004 to 2966 cubic hectometers in 2007). ${ }^{8}$ Of the various water users, Table 1 shows that Agriculture (Sector 1), Energy (Sector 2), Food Production (Sector 3), Other Industries ${ }^{9}$ (Sector 4) and, to a lesser extent, Construction (Sector 5) reduced their water consumption. However, all Private Services (Sectors 6 to 9) increased their water consumption. Of the tertiary activities, only Public Services (Sector 10) slightly reduced their water consumption. In total, the production system decreased water consumption by 138 cubic hectometers (from 2592 to 2454), which represents a decrease of approximately $5.32 \%$.

\footnotetext{
${ }^{5}$ Data on water consumed by agents in Catalonia is not periodically constructed and only information from isolated years (2004, 2005 and 2007) and different estimations is currently available.

6 This information was constructed by the authors from estimations available in Mujeriego (2008) and Sangrà (2008).

${ }^{7}$ Water losses cannot be identified from the data.

${ }^{8}$ The information on water uses shows the distribution of the total amount of water available among the various users. This total value is determined by hydrological planning, which establishes the regional amount of water to be used and depends on rainfall, the capacity of reservoirs, and the flow of rivers at a given time.

${ }^{9}$ Other Industry contains, for example, chemistry, textiles and machinery.
} 
Table 1 Water use in Catalonia $\left(\mathrm{hm}^{3}\right.$ per year)

\begin{tabular}{lrrr}
\hline Sector & 2004 & 2007 & Change (\%) \\
\hline 1. Agriculture & 2268 & 2114 & $-6.79 \%$ \\
2. Energy & 10 & 9 & $-10.00 \%$ \\
3. Food Production & 33 & 31 & $-6.06 \%$ \\
4. Other Industry & 138 & 127 & $-7.97 \%$ \\
5. Construction & 13 & 12 & $-7.69 \%$ \\
6. Commerce & 8 & 11 & $37.50 \%$ \\
7. Transport & 10 & 13 & $30.00 \%$ \\
8. Finance & 7 & 10 & $42.85 \%$ \\
9. Private Services & 78 & 101 & $29.48 \%$ \\
10. Public Services & 27 & 26 & $-3.70 \%$ \\
Total production & 2592 & 2454 & $-5.32 \%$ \\
Residential & 574 & 512 & $-10.80 \%$ \\
Total regional & 3167 & 2966 & $-6.34 \%$ \\
\hline
\end{tabular}

Residential water consumption decreased at a greater percentage than consumption in the production system. Specifically, Table 1 shows that the amount of residential water consumed fell from 574 cubic hectometers in 2004 to 512 in 2007, which is a decrease of around $10.8 \%$. This suggests that final users made a great effort to move towards a more sustainable and more efficient consumption of water.

Comparison of annual water consumption by the various users provides interesting information for water management policies because the individual trends are not symmetrical. This is important when water measures are applied to different agents, especially bearing in mind that the expected impacts could be influenced by the specific behaviour of the various water users.

\subsubsection{Economic Variables}

To analyse changes in water intensity, economic data specifically comprising sectoral value added and regional GDP must also be used. These variables are published by the Statistical Institute of Catalonia (IDESCAT 2018). To avoid price distortions, the 2004 economic data was rescaled to 2007 prices. In particular, sectoral value added $\left(V A_{j}\right)$ and regional GDP in 2004 were valuated at the 2007 price levels using individual price indices that reflect the particular price changes of the various production sectors. For the service activities, the corresponding price indices were obtained from the Consumption Prices Indices (INE 2018a), which individually consider the various categories of consumption goods. For the industrial activities, the price indices were obtained from the Production Prices Indices (INE 2018b). Finally, the $G D P$ in 2004 was rescaled to the price levels in 2007 by applying the general consumption price index of the regional economy (INE 2018a).

For the 2 years, the variables have an identical sectoral disaggregation consisting of one aggregated primary sector (Agriculture), three industrial activities (Energy, Food Production and Other Industry), a Construction sector, and five service sectors (Commerce, Transport, Finance, Private Services and Public Services). Table 2 shows the main economic indicators used in the empirical application. ${ }^{10}$ The price indices (final column in Table 2) show general

\footnotetext{
${ }^{10}$ Unlike water statistics, which are only available for isolated periods, the data in Table 3 come from economic variables published periodically by both the Catalan and Spanish statistical offices.
} 
Table 2 Economic indicators. Catalonia

\begin{tabular}{|c|c|c|c|c|}
\hline \multirow[t]{2}{*}{ Sector } & \multicolumn{2}{|c|}{ Value added $\left(V A_{j}\right)$ (Million Euros) } & \multirow[b]{2}{*}{ Change (\%) } & \multirow[t]{2}{*}{ Price index (base 2007) } \\
\hline & $2004^{\mathrm{a}}$ & 2007 & & \\
\hline 1. Agriculture & 2285 & 2048 & $-10.37 \%$ & 0.85 \\
\hline 2. Energy & 3380 & 3298 & $-2.43 \%$ & 0.75 \\
\hline 3. Food Production & 5084 & 4846 & $-4.68 \%$ & 0.85 \\
\hline 4. Other Industry & 33,957 & 32,402 & $-4.58 \%$ & 0.87 \\
\hline 5. Construction & 18,720 & 22,305 & $19.15 \%$ & 0.87 \\
\hline 6. Commerce & 37,877 & 38,164 & $0.76 \%$ & 0.83 \\
\hline 7. Transport & 8426 & 8586 & $1.90 \%$ & 0.81 \\
\hline 8. Finance & 8100 & 9564 & $18.07 \%$ & 0.83 \\
\hline 9. Private Services & 40,775 & 48,134 & $18.05 \%$ & 0.88 \\
\hline 10. Public Services & 20,393 & 23,386 & $14.70 \%$ & 0.88 \\
\hline Total value added & 184,005 & 192,733 & $4.74 \%$ & CPI (base 2007) \\
\hline GDP & 203,325 & 212,391 & $4.46 \%$ & 0.84 \\
\hline
\end{tabular}

a 2004 variables are valuated at 2007 prices

increases in Catalan prices during the period analysed. In particular, the consumption price index (CPI), used for rescaling regional GDP, increased by $16 \%$ and the sectoral indices, used to rescale sectoral value added, show the largest sectoral price inflation in Energy (Sector 2) and Transport (Sector 7).

The total value added increased by around $4.7 \%$ in real terms (from 184,005 million euros in 2004 to 192,733 million euros in 2007). Despite these results, the value added of the various production sectors clearly behaved asymmetrically; the real value added in Agriculture (Sector 1) and all the Industrial sectors (Sectors 2 to 4) decreased, while it increased in Construction and all Services without exception (Sectors 6 to 10). This increase is especially significant for Construction (Sector 5, 19.15\%), Private Services (Sector 9, 18.05\%), and Finance (Sector 8, $18.07 \%$ ). In addition, the value added in Public Services (Sector 9) increased sharply (by approximately $14.7 \%) .{ }^{11}$ These sectoral trends illustrate an intensification of the importance of services during this period and a decrease in both industrial and agricultural specialization.

In parallel to gross value added, the final row in Table 2 shows a rise of $4.46 \%$ in regional GDP between 2004 and 2007 (from 203,325 million euros in 2004 to 212,391 million euros in 2007).

\section{Empirical Application to Catalonia}

Water intensity makes it possible to relativize the (absolute) water variables by linking water use to the production activity and social characteristics of the economy. In this section, the first calculation refers to the water intensity indicator both for the sectors of production and for residential users. In Fig. 1, which illustrates the individual importance in water intensity $\left(\frac{D}{G D P}\right)$ in the 2 years analysed, the units of measurement are $\mathrm{hm}^{3}$ of water per GDP (in thousand euros). ${ }^{12}$

\footnotetext{
${ }^{11}$ As a result of these increases, during the period 2001-2010 the contribution of Construction to regional value added evolved from $7.8 \%$ to $10.2 \%$ (IDESCAT 2018). Similarly, the contribution of Services to value added evolved from $63.1 \%$ in 2001 to $68.8 \%$ in 2010 (IDESCAT 2018).

${ }^{12}$ Different units of measurement can be used to calculate water intensity. See, for instance, Spang et al. (2014) who used different indicators to obtain water intensity for energy production worldwide.
} 


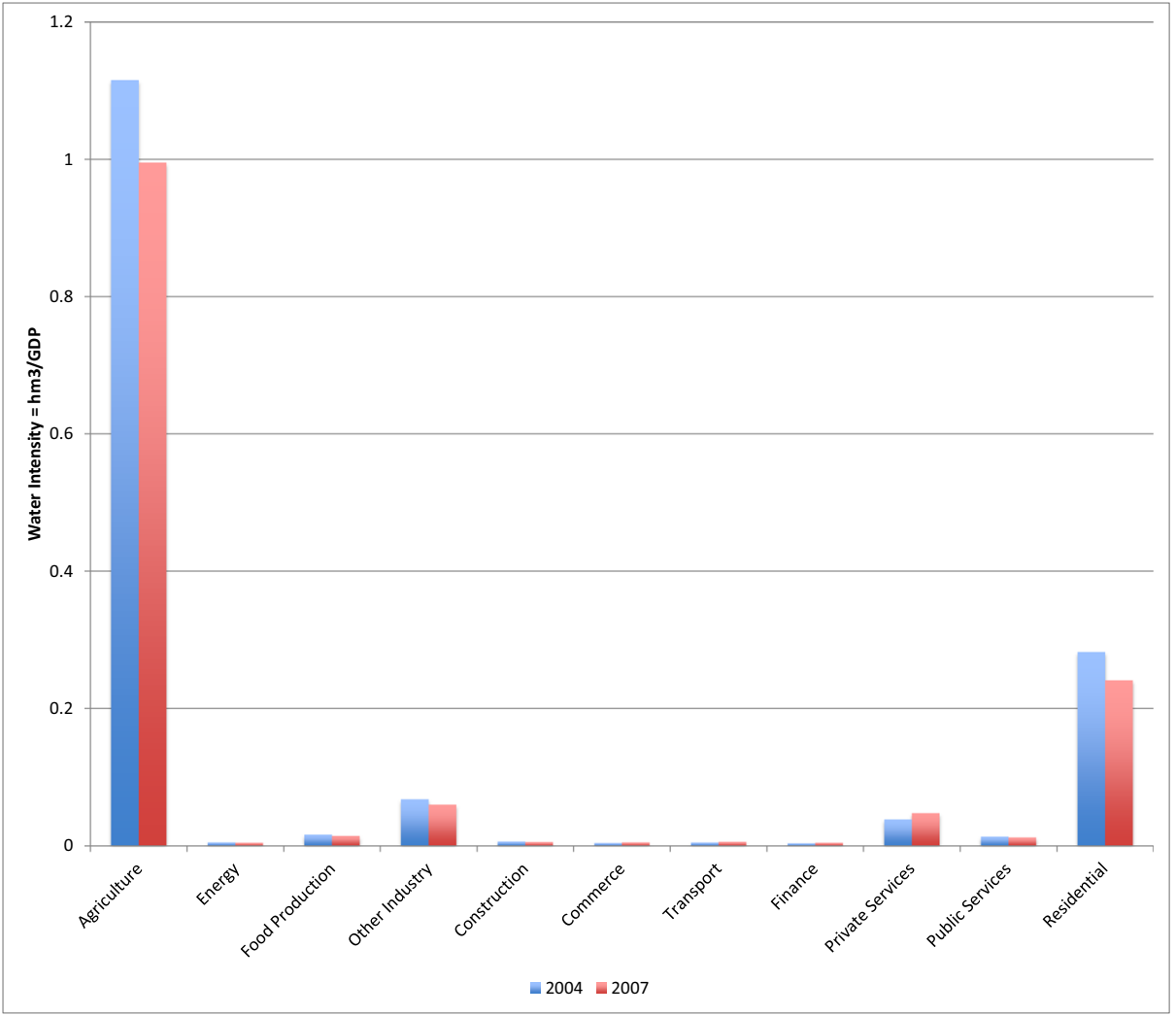

Fig. 1 Water intensity in Catalonia $\left(\frac{D}{G D P}\right)$ in 2004 and 2007

A quick glance at Fig. 1 shows that there are two major contributors to water intensity, i.e. Agriculture (Sector 1) and, at a considerable distance, Residential users. The influence of the other production sectors is much lower, and only Other Industry (Sector 4) and Private Services (Sector 9) have water intensity values above $5 \%$.

Comparison of these 2 years shows that changes in water intensity for the two heaviest users (Agriculture and Residential) are negative, which implies that these consumers gained efficiency in their uses of water in total terms. In other words, the reduction in the water use intensity of agricultural and residential consumers suggests that the situation with regard to water pressure caused by these users is more sustainable. However, we can also see from Fig. 1 that from 2004 to 2007 there was an increase in water use intensity by Private Services (Sector 9).

If the changes in water intensity (Expression (4)) are decomposed, we can visualize the hidden trends that contribute to modifying the water indicator. Table 3 divides the change in total water intensity into the sectoral water intensity effect (i.e. changes in sectoral water used in relation to sectoral value added), the sectoral production intensity effect (i.e. changes in sectoral value added in relation to regional GDP) and the residential water intensity effect (i.e. changes in residential water use in relation to regional GDP). In this table, the units of measurement are $\mathrm{hm}^{3}$ of water per GDP (in thousand euros). 
Table 3 Decomposition of Water Intensity $\left(\mathrm{hm}^{3}\right.$ of water per GDP)

\begin{tabular}{lccc}
\hline Sector & Water intensity effect & Production intensity effect & Total effect \\
\hline 1. Agriculture & 0.0413 & -0.1614 & -0.1201 \\
2. Energy & -0.0003 & -0.0003 & -0.0006 \\
3. Food Production & -0.0005 & -0.0014 & -0.0019 \\
4. Other Industry & -0.0020 & -0.0058 & -0.0078 \\
5. Construction & -0.0015 & 0.0008 & -0.0007 \\
6. Commerce & 0.0011 & -0.0002 & 0.0010 \\
7. Transport & 0.0013 & -0.0001 & 0.0011 \\
8. Finance & 0.0004 & 0.0005 & 0.0009 \\
9. Private Services & 0.0039 & 0.0052 & 0.0091 \\
10. Public Services & -0.0023 & 0.0012 & -0.0011 \\
Total sectors of production & 0.0414 & -0.1615 & -0.1201 \\
Residential Water Intensity Effect & & & -0.0412 \\
Total water intensity effect & & & -0.1613 \\
\hline
\end{tabular}

The sectoral water intensity effect (the first column in Table 3) shows a combination of positive and negative values. Here, Agriculture (Sector 1) leads the positive impact (0.0413) and is followed at a significant distance by Private Services (Sector 9) (0.0039). For these sectors, the positive water intensity effect reflects an increase in the water used in relation to sectoral value added, which implies a reduction in the water efficiency of these activities. On the other hand, Energy (Sector 2), Food Production (Sector 3), Other Industries (Sector 4), and Public Services (Sector 10) contribute negatively to the sectoral water intensity effect, which indicates greater efficiency in the use of water during the period 2004-2007. By adding these individual impacts, the total change in water intensity caused by water use in the production system is 0.0414 , which indicates a positive contribution to the changes in regional water intensity.

The second column in Table 3 shows how the changes in the production structure (sectoral value added in relation to total GDP) have influenced water use intensity. This column shows that the production structure negatively affected water intensity $(-0.1615)$ in total terms. This result is due to individual asymmetric impacts: while Agriculture (Sector 1), Food Production (Sector 3), Other Industries (Sector 4), Commerce (Sector 6) and Transport (Sector 7) negatively influenced the production structure that contributed to decreasing water intensity, Construction (Sector 5), Finance (Sector 8), Private Services (Sector 9) and Public Services (Sector 10) had a positive impact.

The final column in Table 3 shows the total contribution to water intensity. The impacts are negative for Agriculture (Sector 1), Energy (Sector 2), Food Production (Sector 3), Other Industries (Sector 4), Construction (Sector 5), and Public Services (Sector 10). Interestingly, the values are positive for the other sectors, which comprise all the private service activities. If we add these individual trends, we can see that the production system as a whole affected regional water intensity negatively $(-0.1201)$.

Table 3 also shows that the changes in residential uses negatively affected water intensity. This means that the water consumed by final demand in relation to regional production decreased between 2004 and 2007. This reduction is quantified at -0.0412 .

Finally, if we combine (i.e. add) the negative contribution of the production system to that of residential users, there is a (greater) reduction in total water intensity $(-0.1613)$.

Two factors largely explain the changes in regional water intensity, specifically comprising the decrease in Agriculture's contribution to GDP $(-0.1614)$ and the reduction in residential 
water use related to GDP $(-0.0412)$. The former is a feature of the changes in the regional production structure observed in the last few decades. ${ }^{13}$ The later has shown a non-increasing evolution during the period under study. ${ }^{14}$

\section{Discussion}

The above results suggest that the various water consumers and components of water intensity evolved asymmetrically over the period studied. The total reduction in water intensity is the result of adding components with different signs and therefore comprise different dynamic adaptations in terms of the pressure exerted on the natural resource. In total terms, the production system increased its water consumption in relation to its value added, while the changes in the production structure were linked to a negative impact. These outcomes indicate that the ability to control water pressure could be considerably limited since water intensity is not temporally linked to consumption decisions but to changes in the production structure. Since the production structure is affected by aspects such as the economic cycle, production specialization, and production capacities, monitoring water uses could depend on issues outside the strict context of the water system. Successful water management may therefore also involve (more general) economic goals and economic variables than those from the specific hydrological context. By considering the results in Zhang and Zhang (2014), a reduction in China's water intensity is due to the opposite effects that the ones obtained for Catalonia (i.e. an increase in the industrial structure effect and a (larger) decrease in water intensity uses). These different outcomes, which may be dependent on the economy under consideration, the method used and the period of analysis, reinforce the importance of integrating production and consumption issues in the study of temporal changes in water usages.

In addition, special attention should be paid to the agricultural sector in the region's economy. This sector is the greatest consumer of water (its water usage is over $70 \%$ of the total), so its influence on water resources is the highest of all users. Our results show that the contribution of agriculture to the decrease in total water intensity is explained by the reduction in its relative contribution to regional GDP despite its increased water consumption in relation to value added. The positive impact of agriculture is therefore due more to economics (i.e. a drop in the relative importance of production) than to a greater efficiency in water use (i.e. water usage in relation to value added). This indicates that, in order to guarantee its success, any water measure applied to the regional economy should take into consideration the important role of agriculture. This result is in line with Llop (2013) that, through the use of the input-output modeling, showed the largest importance of agriculture in the water distribution at the regional level.

The decomposition proposed in this study illustrates the importance of breaking down overall changes in water intensity into their driving determinants. The changes in an economy's water consumption result from the combination of a huge number of individual effects that are extremely difficult to identify when the analysis is limited to the final aggregated impacts. The empirical results presented in this paper clarify some of the hidden factors and their individual influence on water intensity and water pressure. Environmental policy makers responsible for

\footnotetext{
${ }^{13}$ For example, in 2000 the contribution by Agriculture was around 1.5\% of regional GDP and in 2007 it was $0.92 \%$ (IDESCAT 2018).

${ }^{14}$ According to ACA (2010), from 2002 to 2010 registered domestic water use decreased by around $-1.5 \%$.
} 
water management should take these effects into account, especially when developing water measures aimed at achieving a more sustainable use of water.

\section{Conclusions}

This paper analysed changes in water use intensity in Catalonia between 2004 and 2007 by dividing these changes into three components: the sectoral water intensity effect, the sectoral output intensity effect, and the residential water intensity effect. The sectoral water intensity effect shows the impact on water intensity of changing the amount of water consumed by each sector in relation to its value added. The sectoral output intensity effect shows the impact of changing the sectoral value added in relation to regional GDP. Finally, the residential water intensity effect shows the contribution made by the changes in the residential uses of water in relation to GDP. Identifying these individual terms provides valuable new information that would be impossible to discern by calculating aggregate water use intensity.

These results show a decrease in regional water intensity, which is the consequence of combining various factors with different dynamic behaviours. One interesting finding is that inter-annual changes in the region's water use intensity are largely explained by two factors: first, the lower contribution of agriculture to GDP; and second, the reduction in residential water uses in relation to regional GDP. These results show that these partial aspects of water use are the factors that most influence water pressure in Catalonia.

Data deficiencies in this analysis should also be taken into account. Specifically, the study is limited to two periods that do not represent a complete dynamic trend for water use in Catalonia. To facilitate water analysis at the regional level, efforts should be made to improve water statistics not only in terms of the time periods covered but also in terms of the details provided in relation to the agents involved in water use. Despite these data restrictions with regard to Catalan water uses, the method proposed in this paper could be applied to other geographical contexts that are more periodically covered by statistics. This would allow for a more precise assessment of changes in water intensities over time.

Water management is one of the most important environmental issues regional and local authorities will face in the immediate future, especially in areas that are affected to some extent by water scarcity. Indeed, the global challenges in water issues will be addressed only if important research efforts are made to help water-policy decision processes. The need to guarantee water resources for individuals and firms, to avoid water pollution, and to cope with water-induced changes due to climate change will continue to require much attention in the next few years. To achieve these goals, accurate tools for analysing water issues are needed. The results presented in this paper make it possible to reveal some of the underlying factors that affect water use and help to clarify the complex questions that affect an economy's water consumption. Such knowledge is extremely valuable for designing sustainable water strategies.

Acknowledgements Useful comments and suggestions by two anonymous referees and by the Editors of the journal have substantially improved a previous version. The author gratefully acknowledges the financial support from the Spanish Ministry of Economy and Competitiveness and the European Regional Development Fund (grant ECO2016-75204-P AEI/FEDER, UE), the Government of Catalonia (grant SGR2017-159 and "Xarxa de Referència d'R+D+I en Economia Aplicada"), and the Universitat Rovira i Virgili (grant PFR2019). 


\title{
Compliance with Ethical Standards
}

\author{
Conflict of Interest None.
}

Open Access This article is distributed under the terms of the Creative Commons Attribution 4.0 International License (http://creativecommons.org/licenses/by/4.0/), which permits unrestricted use, distribution, and reproduction in any medium, provided you give appropriate credit to the original author(s) and the source, provide a link to the Creative Commons license, and indicate if changes were made.

\section{References}

ACA (2008) Water in Catalonia: diagnosis and proposals for action. Catalan Water Agency, Generalitat de Catalunya, Barcelona

ACA (2010) Catalan water management plan. Catalan Water Agency, Generalitat de Catalunya, Barcelona

Alcántara V, Del Río P, Hernández F (2010) Structural analysis of electricity consumption by productive sectors. The Spanish case. Energy 35:2088-2098. https://doi.org/10.1016/j.energy.2010.01.027

Di Cosmo V, Hyland M, Llop M (2014) Disentangling water usage in the European Union: a decomposition analysis. Water Resour Manag 28(5):1463-1479. https://doi.org/10.1007/s11269-014-0566-6

Dietzenbacher E, Los B (1998) Structural decomposition techniques: sense and sensitivity. Econ Syst Res 10: 307-323. https://doi.org/10.1080/09535319800000023

EEA (2017) Water intensity of crop production. European Environment Agency

Gowdy JM, Miller JL (1987) Technological and demand change in energy use: an input-output analysis. Environ Plan A 19:1387-1398. https://doi.org/10.1068/a191387

Guerra AI, Sancho F (2011) An analysis of primary energy requirements and emission levels using the structural decomposition approach: the Spanish case. In: Llop M (ed) Air pollution: economic modelling and control policies. Bentham E-Books Series. https://doi.org/10.2174/97816080521721110101

Hadjikakou M, Miller G, Chenoweth J, Druckman A, Zoumides C (2015) A comprehensive framework for comparing water use intensity across different tourist types. J Sustain Tour 23(10):1445-1467. https://oi. org/10.1080/09669582.2015.1044753

Han X, Lakshmanan TK (1994) Structural changes and energy consumption in the Japanese economy 19751985: an input-output analysis. Energy 15:165-188

IDESCAT (2018) Producte Interior Brut de Catalunya. Institut d'Estadística de Catalunya, Barcelona

INE (2018a) Índice de Precios al Consumo. Instituto Nacional de Estadística, Madrid

INE (2018b) Índice de Precios de Producción. Instituto Nacional de Estadística, Madrid

Legesse G, Cordeiro MRC, Ominski KH, Beauchemin KA, Kroebel R, McGeough EJ, Pogue S, McAllister TA (2018) Water use intensity of Canadian beef production in 1981 as compared to 2011. Sci Total Environ 619620:1030-1039. https://doi.org/10.1016/j.scitotenv.2017.11.194

Llop M (2013) Water reallocation in the input-output model. Ecol Econ 86:21-27. https://doi.org/10.1016/j. ecolecon.2012.10.020

Llop M, Ponce-Alifonso X (2012) A never-ending debate: demand versus supply water policies. A CGE analysis for Catalonia. Water Policy 14(4):694-708. https://doi.org/10.2166/wp.2012.096

Llop M, Ponce-Alifonso X (2015) Identifying the role of final consumption in structural path analysis: an application to water uses. Ecol Econ 109:203-210. https://doi.org/10.1016/j.ecolecon.2014.11.011

Llop M, Ponce-Alifonso X (2016) Water and agriculture in a Mediterranean region: the search for a sustainable water policy strategy. Water 8(2):1-14. https://doi.org/10.3390/w8020066

Mendiluce M, Pérez-Arriaga I, Ocaña C (2010) Comparison of the evolution of energy intensity in Spain and in the EU15. Why is Spain different? Energ Policy 38(1):639-645. https://doi.org/10.1016/j.enpol.2009.07.069

Mujeriego R (2008) Alternatives d'abastament de l'aigua. Aigua: font de vida, font de risc, Informe 2008 de l'Observatori del Risc, chapter 3

Ostos JR, Tello E (2014) A long-term view of water consumption in Barcelona (1860-2011): from deprivation to abundance and eco-efficiency? Water Int 39(5):587-605. https://doi.org/10.1080/02508060.2014.951252

Rose A, Casler S (1996) Input-output structural decomposition analysis: a critical appraisal. Econ Syst Res 8:3362. https://doi.org/10.1080/09535319600000003 
Sangrà JM (2008) Qui paga l'aigua?. Aigua: font de vida, font de risc, Informe 2008 de l'Observatori del Risc, chapter 5

Spang ES, Moomaw WR, Gallagher KS, Kirshen PH, Marks DH (2014) Multiple metrics for quantifying the intensity of water consumption of energy production. Environ Res Lett 9:105003. https://doi.org/10.1088 $/ 1748-9326 / 9 / 10 / 105003$

Su B, Ang BW (2012) Structural decomposition analysis applied to energy and emissions: some methodological developments. Energy Econ 34:177-188. https://doi.org/10.1016/j.eneco.2011.10.009

Termes M, Guiu R (2009) Anàlisi de la tendència del consum d'aigua a Catalunya i marges d'estalvi. Nota d'Economia 93-94:21-33

United Nations (2006) Integrated environmental and economic accounting for water resources. Draft for discussion. United Nations Statistics Division, May 2006

Wang Y, Wang H (2005) Sustainable use of water resources in agriculture in Beijing: problems and countermeasures. Water Policy 7:345-357. https://doi.org/10.2166/wp.2005.0022

Zhang C, Zhang H (2014) Can regional economy influence China's water use intensity?: based on refined LMDI method. Chinese Journal of Population Resources and Environment 12(3):247-254. https://doi.org/10.1080 $/ 10042857.2014 .934949$

Publisher's Note Springer Nature remains neutral with regard to jurisdictional claims in published maps and institutional affiliations. 